\title{
Deteksi dan Pencegahan Serangan Wormhole pada Protokol Routing AOMDV Menggunakan Gabungan Metode Delphi dan RTT-TC pada Jaringan MANET
}

\author{
(Detection and Prevention of Wormhole Attacks on the AOMDV Routing Protocol \\ Using Delphi and RTT-TC Method on MANET)
}

Nini Kurnia Safitri, Andy Hidayat Jatmika, Moh. Ali Albar

Program Studi Teknik Informatika, Fakultas Teknik, Universitas Mataram

Jl. Majapahit 62, Mataram, Lombok NTB, INDONESIA

Email: ninikurniasafitri@gmail.com, [andy, mohalialbar]@unram.ac.id

*Penulis korespondensi

\begin{abstract}
Mobile Ad Hoc Network (MANET) is a network that doesn't have a fixed infrastructure where there is a set of nodes in it. Which the MANET was to be vulnerable to attacks that can interfere with the process of communication and data transmission on the network. One type of attack that can attack the MANET is a wormhole attack. The wormhole is an attack on a network where there are two wormhole nodes that are interconnected using a wormhole link to attack network traffic or discard data packets it receives. To prevent wormhole attacks, the method that can be used is the Delay Per Hop Indicator (Delphi) method and the Round Trip Time and Topological Comparison (RTT-TC) method. The Delphi and RTT-TC methods have their advantages and disadvantages. In this study, it was proposed to combine the Delphi and RTT-TC methods to cover the shortcomings of each method. Based on the results, it can be concluded that the merging of the Delphi and RTT-TC methods can detect and prevent wormhole attacks and improve poor network quality caused by wormhole attacks.
\end{abstract}

Key words: MANET, Wormhole attack, Delphi, RTT-TC.

\section{PENDAhUluan}

Mobile Ad Hoc Network (MANET) adalah jaringan yang terdiri dari beberapa node independen yang mana jaringan ini dapat dibentuk kapan saja dan dimana saja [1]. Node-node pada jaringan MANET melakukan proses komunikasi dan transmisi data dengan adanya suatu protokol routing. Ada 3 jenis tipe protokol routing yakni protokol routing reaktif, proaktif, dan hybrid. Protokol routing reaktif hanya akan melakukan pencarian rute apabila akan dilakukan proses pengiriman data ke suatu tujuan dengan cara mem-broadcast sebuah pesan. Pada penelitian ini, protokol routing yang akan diteliti adalah protokol routing reaktif, yakni Ad Hoc On Demand Multipath Distance Vector (AOMDV). Protokol routing AOMDV memiliki dua fitur, yakni route discovery dan route maintenance. Proses route discovery merupakan proses pencarian rute dari node sumber ke node tujuan dengan cara menyebarkan paket route request (RREQ) ke tetangganya. Sedangkan route maintenance merupakan proses pemeliharaan rute, dimana suatu node kirim paket route error (RERR) ke node sumber kalau terjadi kerusakan rute.

Wormhole merupakan suatu serangan pada jaringan dimana terdapat dua atau lebih wormhole node yang saling terhubung dan bekerja sama untuk menyerang lalu lintas jaringan ataupun membuang paket data yang diterimanya. Setiap wormhole node akan saling terhubung menggunakan wormhole link [2]. Proses route discovery pada AOMDV cukup rentan terhadap serangan wormhole, khususnya pada proses broadcast paket RREQ. Ketika proses broadcast paket RREQ berlangsung, wormhole node yang mengetahui adanya paket RREQ akan merespon paket RREQ dan mengklaim bahwa wormhole node tersebut punya rute paling pendek dan terbaru menuju node tujuan. Sehingga, rute yang terpilih untuk mengirim paket data adalah rute yang memiliki wormhole node. Hal ini akan membuat lalu lintas jaringan menjadi terganggu dan wormhole node dapat membuang paket data yang diterimanya.

Wormhole link memiliki ukuran yang sangat panjang, namun wormhole node dapat mengklaim bahwa dengan melewati wormhole link tersebut maka rute yang ditempuh untuk sampai ke tujuan akan lebih cepat. Sehingga untuk mendeteksi serangan wormhole, dibutuhkan metode yang dapat mendeteksi adanya wormhole link tersebut. Metode yang dapat digunakan adalah metode Delay Per Hop Indicator (Delphi) dan metode Round Trip Time and Topological Comparison (RTT-TC). Metode Delphi mendeteksi serangan wormhole dengan menghitung delay di setiap hop dari node sumber ke node tujuan. Ketika jaringan dalam kondisi normal, delay antar hop sama di sepanjang rute. Tetapi, pada saat terkena serangan wormhole, maka nilai delay akan menjadi tinggi karena adanya wormhole link yang menghubungkan wormhole node [3]. Sedangkan pada metode RTT-TC, serangan 
wormhole dideteksi dengan menghitung nilai round trip time dan topological comparison. Topological comparison berfungsi untuk mendeteksi apakah terdapat wormhole link disuatu rute atau tidak pada suatu jaringan [4].

Metode Delphi dan RTT-TC memiliki kelebihan dan kekurangannya masing-masing. Kelebihan metode Delphi adalah dapat mendeteksi wormhole dengan menghitung delay per hop setiap node, namun tidak dapat menandai lokasi wormhole [5]. Sedangkan, kelebihan metode RTTTC adalah dapat menandai lokasi wormhole dan menyimpan wormhole tersebut pada detected list (DET list) node sumber, namun penggunaan RTT dalam mendeteksi wormhole kurang reliable [4], sehingga pada penelitian ini diusulkan penggabungan metode Delphi dan RTT-TC untuk meningkatkan kinerja metode dalam mendeteksi dan mencegah serangan wormhole.

Pada penelitian ini akan dilakukan pendeteksian dan pencegahan serangan wormhole pada protokol routing AOMDV menggunakan metode Delphi, RTT-TC, serta gabungan metode Delphi dan RTT-TC.

\section{Penelitian Terkait}

Pada penelitian yang berjudul Detection and Prevention of Wormhole Attack on AOMDV Routing Protocol using Hop-count and Communication range in $W S N$, dilakukan pengujian untuk mengetahui kinerja metode Hop-count dalam mendeteksi serangan wormhole pada protokol routing AOMDV. Pengujian dilakukan dengan menggunakan jumlah node yang beragam, yakni 30, 50, dan 70 node dengan jumlah wormhole node yang digunakan adalah 2 node. Untuk mengetahui perbandingan kinerja metode Hop-count pada jaringan, maka digunakan parameter uji packet delivery ratio, throughput, dan jumlah packet drops. Hasil pengukuran kinerja metode Hop-count menggunakan parameter uji packet delivery ratio berubah-ubah namun cenderung meningkat seiring dengan peningkatan jumlah node, yakni 98,68\%, 92,86\%, dan 99,58\%. Kemudian nilai throughput semakin meningkat dengan bertambahnya jumlah node, yakni 20,48 Kbps, 30,72 Kbps, dan 38,912 Kbps. Jumlah paket yang di-drop juga berubah-ubah seiring dengan peningkatan jumlah node. Pada saat jumlah node 30 , jumlah paket drop adalah 2 paket, pada saat jumlah node 50, jumlah paket drop adalah 19 paket, sedangkan pada saat jumlah node 70, jumlah paket drop adalah 2 paket. Berdasarkan hasil pengujian tersebut, dapat disimpulkan bahwa metode Hop-count dapat mendeteksi serangan wormhole dengan baik [6].

Pada penelitian [7] dilakukan pencegahan serangan wormhole pada protokol routing AODV menggunakan metode Delphi. Dari hasil simulasi, dapat diketahui bahwa pada saat pencegahan serangan wormhole nilai throughput adalah $33 \%$ dan nilai delay $37 \%$. Sedangkan jumlah packet loss ratio adalah $31 \%$, hal ini disebabkan karena adanya paket drop. Dari hasil simulai dapat disimpulkan bahwa metode Delphi dapat mendeteksi dan mencegah serangan wormhole. Metode ini dapat membantu mengurangi packet loss dan meningkatkan nilai throughput [7].
Pada penelitian [4] dilakukan pengujian terhadap protokol AODV dengan parameter uji detection rate dan accuracy of alarm. Dari hasil simulasi dapat diketahui bahwa, tingkat detection rate mencapai $98 \%$ pada saat penggunaan metode RTT dan mencapai $100 \%$ pada saat penambahan metode topological comparison. Sedangkan, tingkat accuracy of alarm mencapai $88 \%$ pada saat penggunaan metode RTT dan meningkat menjadi $95 \%$ dengan penambahan metode topological comparison. Sehingga, dapat disimpulkan bahwa penggunaan metode RTT-TC untuk mendeteksi dan mencegah serangan wormhole sangat baik, hal ini dapat diketahui berdasarkan parameter uji yang digunakan yakni detection rate dan accuracy of alarm memberikan nilai yang cukup tinggi [4].

Pada penelitian [8] dilakukan evaluasi terhadap performansi protokol routing AODV dan DSR pada saat terdapat serangan wormhole dan pada saat tidak ada serangan wormhole. Dari hasil simulasi protokol routing AODV dan DSR pada saat tidak ada wormhole, dapat diketahui bahwa nilai PDR AODV dan DSR sama-sama meningkat seiring dengan peningkatan jumlah node, nilai PDR AODV meningkat dari $0,50 \%$ hingga $0,96 \%$ dan nilai PDR DSR meningkat dari $0,52 \%$ hingga $1 \%$. Nilai end-toend-delay AODV dan DSR sama-sama menurun seiring dengan peningkatan jumlah node, nilai average end-to-end delay AODV menurun dari $200 \mathrm{sec}$ hingga $10 \mathrm{sec}$ dan nilai average end-to-end delay DSR menurun dari $1600 \mathrm{sec}$ hingga $10 \mathrm{sec}$. Sedangkan, AODV dan DSR memiliki nilai throughput yang sama dan sama-sama meningkat, yakni dari 8 kbps hingga 120 kbps. Kemudian, dari hasil simulasi protokol routing AODV dan DSR pada saat terdapat serangan wormhole, dapat diketahui bahwa nilai PDR AODV dan DSR menurun seiring dengan peningkatan jumlah node, nilai PDR AODV menurun dari $1 \%$ hingga $0,1 \%$ dan nilai PDR DSR menurun dari $0,96 \%$ hingga $0,21 \%$. Nilai end-to-end-delay AODV meningkat dari 0 sec hingga $9 \mathrm{sec}$ dan nilai average end-to-end delay DSR meningkat dari $0 \mathrm{sec}$ hingga $30 \mathrm{sec}$. Sedangkan, nilai throughput AODV menurun dari 0,4 kbps hingga 0 kbps dan nilai throughput DSR menurun dari 0,6 kbps hingga 0 kbps. Dari hasil simulasi, dapat disimpulkan bahwa performansi protokol routing AODV menunjukkan hasil lebih baik daripada DSR [8].

\section{Metode PENELITIAN}

Tahap pertama yang harus dilakukan pada penelitian ini yaitu melakukan studi literatur dengan mengumpulkan referensi-referensi yang diperlukan, seperti buku, jurnal ataupun website yang berkaitan dengan topik pada penelitian yang diusulkan. Setelah itu dilakukan tahap kedua, yakni mempersiapkan hardware dan software yang digunakan untuk melakukan penelitian. Tahap selanjutnya adalah membuat script serangan wormhole untuk mengetahui efek serangan wormhole terhadap kinerja protokol routing AOMDV. Script simulasi dibuat untuk mengatur jumlah node, jumlah wormhole node, luas area simulasi, dan waktu simulasi yang digunakan. Jika pembuatan script sudah selesai, maka simulasi akan 
dijalankan dan diperoleh output berupa file trace. Proses simulasi dilakukan selama lima kali untuk mengetahui pengaruh serangan wormhole terhadap perubahan kinerja protokol routing AOMDV. Dari simulasi yang telah dilakukan, maka akan diperoleh output yang akan di-filter untuk mengetahui kinerja protokol routing AOMDV standar maupun yang sudah dimodifikasi berdasarkan parameter uji average end-to-end delay, packet delivery ratio (PDR), dan throughput menggunakan tool AWK script. Kemudian dibuat grafik dari hasil filtering file trace dan akan dianalisis masing-masing grafiknya dan diperoleh suatu kesimpulan. Setelah itu dilakukan tahap akhir penelitian yakni pembuatan laporan penelitian.

\section{A. Mekanisme Protokol Routing AOMDV}

AOMDV merupakan salah satu protokol routing yang menerapkan konsep multiple path yang mendukung multipath routing dan merupakan bentuk pengembangan dari AODV, dimana rute yang diperoleh pada saat route discovery yakni lebih dari satu rute dan dapat digunakan sebagai rute cadangan. Protokol routing AOMDV memiliki beberapa karakteristik yang sama seperti protokol routing AODV. Protokol routing AOMDV berbasis vektor dan menggunakan pendekatan hop by hop seperti protokol routing AODV. Seperti AODV, protokol routing AOMDV juga memiliki dua fitur, yakni route discovery dan route maintenance. Sementara itu, perbedaan utama antara protokol routing AODV dan AOMDV adalah jumlah rute yang ditemukan di setiap pencarian rutenya. Pada saat rute sudah ditemukan, AODV hanya memperoleh satu rute, sedangkan AOMDV dapat memperoleh lebih dari satu rute.

Route maintenance merupakan proses pemeliharaan rute. Suatu node akan mengirimkan paket RERR ke node sumber secara unicast jika link yang menghubungkannya dengan node tetangganya terputus. Kemudian tabel routing node sumber akan di periksa, apakah terdapat rute cadangan ke node tujuan yang sama. Jika ada, maka rute dengan jumlah hop terkecil akan dipilih dan paket data dapat langsung dikirimkan. Namun, jika tidak terdapat rute cadangan, maka proses route discovery akan diulangi [9].

\section{B. Mekanisme Serangan Wormhole}

Serangan wormhole merupakan salah satu jenis serangan pada jaringan MANET, dimana terdapat dua wormhole node atau lebih yang terhubung menggunakan sebuah link yang disebut wormhole link. Wormhole node bekerja sama menciptakan ilusi bahwa wormhole node tersebut nampak menjadi node normal, padahal node tersebut merupakan node penyerang. Wormhole membuat dua atau lebih wormhole node untuk mengendalikan lalu lintas proses routing. Wormhole link yang digunakan oleh wormhole node bisa menjadi mekanisme komunikasi yang digunakan oleh jaringan.

Untuk meluncurkan serangan wormhole, sebuah wormhole menghubungkan dua atau lebih wormhole node secara berpasang-pasangan di jaringan menggunakan wormhole link. Dalam proses pencarian rute, wormhole node menerima paket di satu lokasi dan mengirimkannya ke wormhole node lainnya melalui wormhole link dan akan diteruskan ke node normal yang menjadi tetangganya hingga sampai ke node tujuan. Jika rute sudah ditemukan, maka paket data akan dikirimkan melalui rute tersebut dan wormhole node pada rute tersebut akan menjatuhkan paket data yang diterimanya, sehingga menyebabkan terjadinya gangguan jaringan [10].

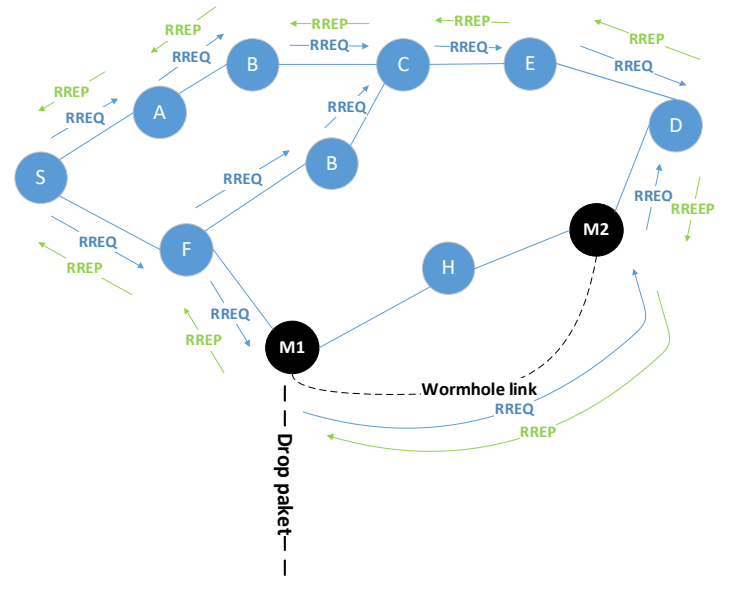

Gambar. 1. Ilustrasi serangan wormhole

Gambar 1 menunjukkan proses pencarian rute dari node $\mathrm{S}$ menuju node $\mathrm{D}$. Node $\mathrm{S}$ akan melakukan broadcast paket RREQ ke node-node tetangganya untuk menemukan rute menuju node $\mathrm{D}$. Pada saat proses broadcast, node M1 menerima paket RREQ. Node M1 segera mengirimkan paket RREQ menuju node M2 melalui wormhole link dengan kecepatan tinggi, sehingga paket RREQ dapat lebih dulu sampai di node D. Node M2 akan meneruskan RREQ ke node tetangganya, yakni node $\mathrm{D}$ yang merupakan node tujuan. Setelah itu, node D akan mengirimkan paket RREP ke node $\mathrm{S}$ melalui reverse path yang melewati node $\mathrm{M} 2$ dan M1. Dengan demikian, rute terpilih yang akan digunakan adalah S-F-M1-M2-D. Jika rute sudah ditemukan, maka akan dilakukan pengiriman paket data. Node M1 yang menerima paket data akan membuang paket data tersebut. Hal ini menyebabkan paket data tidak sampai ke node tujuan.

\section{Metode Delay Per Hop Indicator (Delphi)}

Dalam pendeteksian serangan wormhole, metode Delay Per Hop Indicator (Delphi) mengumpulkan jumlah hop dan informasi delay dari disjoint path dan menghitung nilai delay per hop sebagai indikator untuk mendeteksi serangan wormhole. Dalam situasi normal, delay dalam suatu hop sama dengan delay di setiap hop di sepanjang rute. Namun jika terdapat serangan wormhole, delay antara wormhole node yang satu dengan yang lainnya sangat tinggi karena sebenarnya ada banyak hop di antara wormhole node tersebut. Jika dibandingkan delay per hop dari rute saat situasi jaringan normal dengan delay per hop pada saat terdapat serangan wormhole, delay per hop dari rute saat situasi jaringan normal lebih kecil. Oleh karena itu, jika sebuah rute memiliki nilai delay per hop yang tinggi, maka rute tersebut kemungkinan mengalami serangan wormhole 
[11]. Ketika suatu node menemukan wormhole node, node tersebut akan berhenti meneruskan pesan ke wormhole node tersebut dan akan mengirim blocking message ke node sumber. Node sumber akan mem-broadcast blocking message ke semua node di jaringan agar semua node pada jaringan menghapus ID wormhole node dari tabel routing mereka [12].

Kelebihan metode Delphi adalah dapat mendeteksi serangan wormhole dengan menghitung delay per hop setiap node, dapat mendeteksi dua jenis serangan wormhole, yakni hidden attack dan expose attack, tidak membutuhkan sinkronisasi waktu dan posisi setiap node, dan tidak membutuhkan tambahan hardware untuk mendeteksi serangan wormhole. Sedangkan, kekurangan metode Delphi adalah tidak dapat menandai lokasi wormhole karena metode ini hanya menghitung delay setiap node pada suatu rute dan menyimpulkan bahwa nilai DPH pada rute normal lebih kecil daripada nilai DPH rute yang memiliki tunnel link [13] [14].

\section{Metode Round Trip Time and Topological Comparison (RTT-TC)}

Round Trip Time (RTT) didefinisikan sebagai interval waktu antara kapan paket dikirim dan kapan diterima. Dua wormhole node dengan wormhole tunnel di antaranya biasanya memiliki RTT lebih lama dibandingkan dengan RTT antara dua node normal. Metode RTT-TC berdasarkan pada topological comparison dan pengukuran round trip time. Metode RTT-TC mendeteksi serangan wormhole ketika node sumber menemukan bagian SUS yang tidak kosong dalam neighbor list-nya. Untuk melakukan topological comparison, digunakan enquiry request (ENQ) dan enquiry reply (ENQ $\left.\mathrm{E}_{\mathrm{rep}}\right)$.

Langkah-langkah topological comparison adalah sebagai berikut:

- Setelah dilakukan route discovery, node sumber akan melakukan pengirimkan paket ENQ menuju suspected node yang terdapat pada SUS list node tersebut.

- $\quad$ Suspected node akan membalas paket ENQ dengan mengirim $\mathrm{ENQ}_{\text {rep }}$ yang berisi TRST list dari suspected node.

- Node sumber membandingkan TRST list yang diterima dengan TRST list-nya sendiri. Jika terdapat node yang terkena serangan wormhole, maka ID node tersebut akan disimpan dalam detected list (DET list). DET list digunakan untuk menyimpan node-node yang terkena serangan wormhole. Jika tidak terkena serangan wormhole, maka suspected node dihapus dari SUS list node sumber dan dimasukkan dalam TRST list node sumber [4].

\section{E. Gabungan Metode Delphi dan RTT-TC}

Metode Delphi dan RTT-TC memiliki kelebihan dan kekurangannya masing-masing. Kelebihan metode Delphi adalah dapat mendeteksi wormhole dengan menghitung delay per hop setiap node, namun tidak dapat menandai lokasi wormhole [14]. Sedangkan, kelebihan metode RTTTC adalah dapat menandai lokasi wormhole dan menyimpan wormhole tersebut pada detected list (DET list) node sumber, namun penggunaan RTT dalam mendeteksi wormhole kurang reliable [4]. Sehingga pada penelitian ini diusulkan penggabungan metode Delphi dan RTT-TC untuk menutupi kekurangan masing-masing metode.

Untuk pendeteksian serangan wormhole digunakan perhitungan metode Delphi dan untuk mencegahannya digunakan metode topological comparison. Berikut merupakan diagram alir penggabungan metode Delphi dan metode RTT-TC.

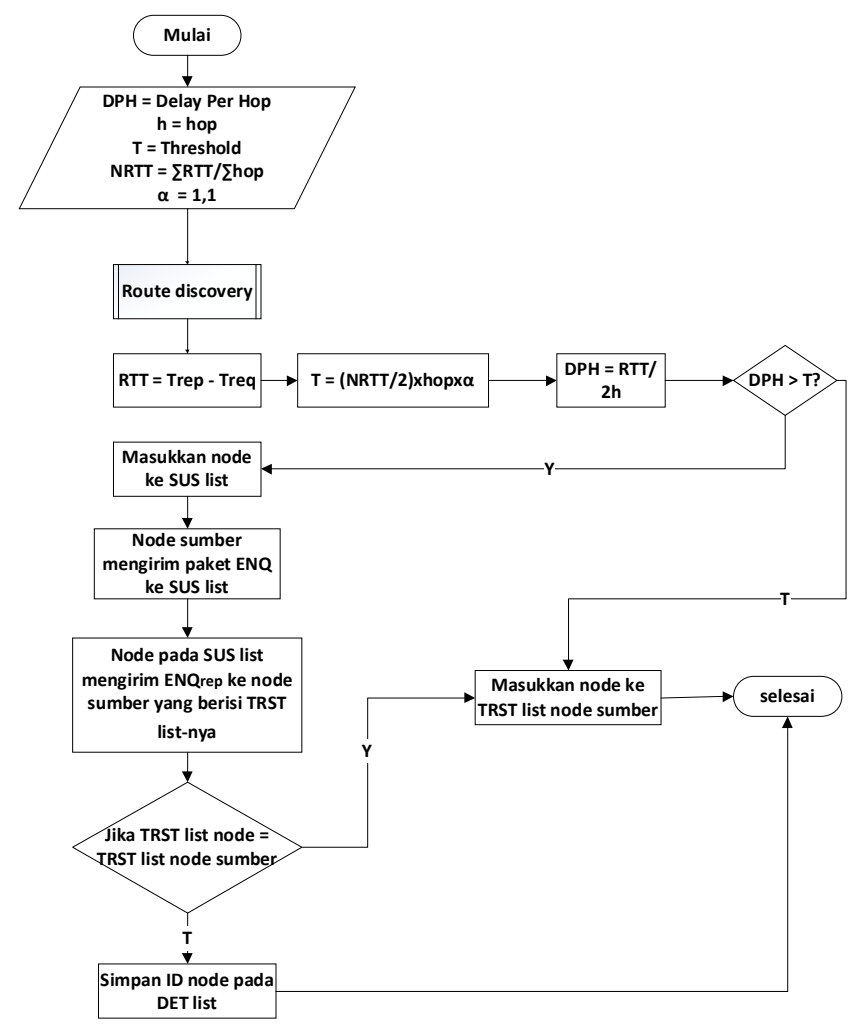

Gambar. 2. Diagram alir gabungan metode Delphi dan RTT-TC

\section{$F$. Lingkungan Simulasi}

Untuk menunjang jalannya simulasi, dibutuhkan beberapa parameter. Parameter-parameter yang dibutuhkan untuk menunjang jalannya simulasi tersaji pada Tabel I.

- Average End-to-End Delay

Average end-to-end delay menghitung rata-rata waktu yang diperlukan suatu paket dari saat paket dikirim sampai diterima oleh node tujuan [15]. Persamaan (1) merupakan rumus yang digunakan untuk menghitung average end-to-end delay:

$$
\text { Average end }- \text { to }- \text { end delay }=\frac{\text { Total delay }}{\text { Total paket yang diterima }}
$$


TABEL I. PARAMETER SimUlasi

\begin{tabular}{|c|c|}
\hline Parameter & Nilai \\
\hline Simulator & NS-2.35 \\
\hline Protokol routing & AOMDV \\
\hline Jenis serangan & Wormhole \\
\hline Jumlah normal node & 2 \\
\hline Jumlah wormhole node & Random Waypoint \\
\hline Luas area simulasi & CBR \\
\hline Model mobilitas & 150 detik \\
\hline Tipe traffic & 802.11 \\
\hline Waktu simulasi & Wireless \\
\hline MAC Layer & dan $1000 \mathrm{x}$ \\
\hline Channel & $\begin{array}{c}\text { Average end-to-end delay, } \\
\text { Packet Delivery Ratio } \\
\text { (PDR), dan Throughput }\end{array}$ \\
\hline Parameter uji
\end{tabular}

- Packet delivery ratio (PDR)

$P D R$ adalah perbandingan jumlah paket data yang berhasil diterima oleh node tujuan dibagi dengan jumlah paket data yang dikirimkan oleh node sumber [15]. Untuk menghitung PDR digunakan rumus pada Persamaan (2) berikut:

$$
P D R=\frac{\text { Jumlah data yang diterima }}{\text { Jumlah data yang dikirim }} \times 100
$$

- Throughput

Throughput yaitu jumlah rata-rata data (bit) yang dikirimkan ke node tujuan per satuan waktu [9]. Untuk menghitung throughput digunakan rumus pada Persamaan (3) berikut:

$$
\text { Throughput }=\frac{\text { Waktu ukuran data yang diterima }}{\text { Waktu pengiriman data }}
$$

\section{HASIL DAN PEMBAHASAN}

Pengujian telah dilakukan pada lima skenario simulasi, yakni simulasi protokol routing AOMDV, simulasi protokol routing AOMDV dengan serangan wormhole, simulasi protokol routing AOMDV dengan serangan wormhole dan penerapan metode Delphi, simulasi protokol routing AOMDV dengan serangan wormhole dan penerapan metode RTT-TC, serta simulasi protokol routing AOMDV dengan serangan wormhole dan penerapan gabungan metode Delphi dan RTT-TC. Setiap skenario simulasi dibagi menjadi dua kondisi, yakni dengan luas area $800 \times 800 \mathrm{~m}^{2}$ dan $1000 \times 1000 \mathrm{~m}^{2}$, dimana disetiap area simulasi kondisi traffic rate akan berubah-ubah mulai dari $0,1 \mathrm{MB} / \mathrm{s}$ hingga $1,0 \mathrm{MB} / \mathrm{s}$. Kemudian setiap hasil simulasi diuji menggunakan parameter uji average end-to-end delay, PDR, dan throughput.

\section{A. Perubahan Average End-to-End delay Terhadap Traffic Rate dan Luas Area}

TABEL II. Kualitas Average END-TO-END DELAy TerhaDAP

\begin{tabular}{|c|c|c|c|c|c|c|}
\hline \multicolumn{7}{|c|}{ Average End-to-End Delay (second) } \\
\hline $\begin{array}{l}\text { Luas } \\
\text { Area } \\
\left(\mathrm{m}^{2}\right)\end{array}$ & $\begin{array}{c}\text { Traffic } \\
\text { Rate }\end{array}$ & AOMDV & $\begin{array}{c}\text { AOMDV + } \\
\text { Wormhole } \\
\text { (WAOMDV) }\end{array}$ & $\begin{array}{c}\text { WAOMDV } \\
+ \\
\text { Delphi }\end{array}$ & $\begin{array}{c}\text { WAOMDV } \\
+ \\
\text { RTT-TC }\end{array}$ & $\begin{array}{c}\text { WAOMDV } \\
+ \\
\text { Gabungan } \\
\text { Metode }\end{array}$ \\
\hline \multirow{10}{*}{$\begin{array}{c}800 \mathrm{x} \\
800 \\
\mathrm{~m}^{2}\end{array}$} & 0.1 & 0.0376 & 0.2312 & 0.0449 & 0.0639 & 0.0432 \\
\hline & 0.2 & 0.0111 & 0.2000 & 0.0178 & 0.0308 & 0.0166 \\
\hline & 0.3 & 0.0093 & 0.1979 & 0.0123 & 0.0209 & 0.0126 \\
\hline & 0.4 & 0.0086 & 0.1382 & 0.0119 & 0.0182 & 0.0123 \\
\hline & 0.5 & 0.0082 & 0.1031 & 0.0109 & 0.0171 & 0.0112 \\
\hline & 0.6 & 0.0075 & 0.1256 & 0.0102 & 0.0158 & 0.0100 \\
\hline & 0.7 & 0.0080 & 0.0890 & 0.0098 & 0.0158 & 0.0094 \\
\hline & 0.8 & 0.0072 & 0.0827 & 0.0092 & 0.0139 & 0.0094 \\
\hline & 0.9 & 0.0074 & 0.0548 & 0.0088 & 0.0129 & 0.0095 \\
\hline & 1.0 & 0.0072 & 0.0465 & 0.0086 & 0.0131 & 0.0092 \\
\hline $\begin{array}{l}\text { Luas } \\
\text { Area } \\
\left(\mathrm{m}^{2}\right)\end{array}$ & $\begin{array}{c}\text { Traffic } \\
\text { Rate }\end{array}$ & AOMDV & $\begin{array}{c}\text { AOMDV + } \\
\text { Wormhole } \\
\text { (WAOMDV) }\end{array}$ & $\begin{array}{c}\text { WAOMDV } \\
+ \\
\text { Delphi }\end{array}$ & $\begin{array}{c}\text { WAOMDV } \\
+ \\
\text { RTT-TC }\end{array}$ & $\begin{array}{c}\text { WAOMDV } \\
+ \\
\text { Gabungan } \\
\text { Metode }\end{array}$ \\
\hline \multirow{10}{*}{$\begin{array}{c}1000 \mathrm{x} \\
1000 \mathrm{~m}^{2}\end{array}$} & 0.1 & 0.0679 & 0.3818 & 0.0859 & 0.1260 & 0.0887 \\
\hline & 0.2 & 0.0159 & 0.3003 & 0.0182 & 0.0389 & 0.0199 \\
\hline & 0.3 & 0.0127 & 0.3134 & 0.0141 & 0.0351 & 0.0166 \\
\hline & 0.4 & 0.0102 & 0.2668 & 0.0127 & 0.0279 & 0.0133 \\
\hline & 0.5 & 0.0098 & 0.2302 & 0.0118 & 0.0247 & 0.0124 \\
\hline & 0.6 & 0.0096 & 0.1829 & 0.0110 & 0.0231 & 0.0121 \\
\hline & 0.7 & 0.0092 & 0.1788 & 0.0108 & 0.0205 & 0.0111 \\
\hline & 0.8 & 0.0089 & 0.1776 & 0.0101 & 0.0171 & 0.0111 \\
\hline & 0.9 & 0.0082 & 0.1270 & 0.0097 & 0.0168 & 0.0112 \\
\hline & 1.0 & 0.0084 & 0.1497 & 0.0096 & 0.0163 & 0.0101 \\
\hline
\end{tabular}
TRAFFIC RATE DAN LUAS AREA

Berdasarkan Tabel II, dapat diketahui bahwa nilai terbaik average end-to-end delay AOMDV pada saat kondisi normal adalah 0,0072 sec kemudian meningkat menjadi 0,0465 sec saat terdapat serangan wormhole. Nilai average end-to-end delay kembali menurun setelah diimplementasikan metode Delphi dan RTT-TC, dimana nilai terbaik average end-to-end delay adalah 0,0086 sec pada saat menggunakan metode Delphi dan 0,0131 sec pada saat menggunakan metode RTT-TC. Pada saat gabungan metode Delphi dan RTT-TC diimplementasikan, nilai average end-to-end delay AOMDV menjadi lebih baik dan hampir mendekati nilai average end-to-end delay AOMDV saat kondisi normal, yakni 0,0092 sec. Sedangkan, nilai average end-to-end delay AOMDV di luas area $1000 \times 1000 \mathrm{~m}^{2}$ mencapai nilai terbaik pada saat kondisi normal yakni 0,0084 sec kemudian meningkat menjadi 0,1497 sec saat terdapat serangan wormhole. Nilai average end-to-end delay kembali menurun setelah diimplementasikan metode Delphi dan RTT-TC dimana nilai terbaik average end-to-end delay adalah 0,0096 sec pada saat menggunakan metode Delphi dan 0,0163 sec pada saat menggunakan metode RTT-TC. Pada saat gabungan metode Delphi dan RTT-TC diimplementasikan, nilai average end-to-end delay AOMDV menjadi lebih optimal dan hampir mendekati nilai average end-to-end delay AOMDV saat kondisi normal, yakni 0,0101 sec.

Berdasarkan pengimplementasian ketiga metode tersebut, yakni metode Delphi, RTT-TC, dan gabungan metode Delphi dan RTT-TC, dapat diketahui bahwa gabungan metode Delphi dan RTT-TC dapat menurunkan delay pada protokol routing AOMDV yang mengalami kenaikan karena adanya serangan wormhole. Selain itu, nilai average end-to-end delay pada luas area $1000 \times 1000$ $\mathrm{m}^{2}$ juga lebih tinggi dibandingkan dengan luas area $800 \mathrm{x}$ 
$800 \mathrm{~m}^{2}$, karena luas area yang semakin bertambah menyebabkan jarak antar node di suatu jaringan menjadi cukup jauh, sehingga menyebabkan semakin panjang rute yang akan dilewati untuk mencapai node tujuan.

\section{B. Perubahan Packet Delivery Ratio (PDR) Terhadap Traffic Rate dan Luas Area}

Berdasarkan Tabel III, pada luas area $800 \times 800 \mathrm{~m}^{2}$ nilai tertinggi PDR AOMDV pada saat kondisi normal adalah $71,836 \%$ kemudian menurun menjadi 30,928\% saat terdapat serangan wormhole. Pada saat metode Delphi dan RTT-TC diimplementasikan, nilai PDR AOMDV meningkat dibandingkan pada saat terkena serangan wormhole dan mencapai nilai tertinggi yakni $48,800 \%$ pada saat menggunakan metode Delphi dan $61,975 \%$ pada saat menggunakan metode RTT-TC. Pada saat gabungan metode Delphi dan RTT-TC diimplementasikan, nilai PDR AOMDV menjadi lebih baik, yakni 67,701\% dan hampir mendekati nilai PDR AOMDV pada saat kondisi normal. Sedangkan, nilai tertinggi PDR AOMDV di luas area 1000 x $1000 \mathrm{~m}^{2}$ saat kondisi normal adalah $68,067 \%$ kemudian menurun menjadi $24,411 \%$ saat terdapat serangan wormhole. Pada saat metode Delphi dan RTT-TC diimplementasikan, nilai PDR AOMDV meningkat dibandingkan pada saat terkena serangan wormhole dan mencapai nilai tertinggi yakni $46,308 \%$ pada saat menggunakan metode Delphi dan $58,978 \%$ pada saat menggunakan metode RTT-TC. Pada saat gabungan metode Delphi dan RTT-TC diimplementasikan, nilai PDR AOMDV menjadi lebih baik dan hampir mendekati nilai PDR AOMDV pada saat kondisi normal yakni $60,848 \%$.

TABEL III. Kualtas PDR TerhadaP TRAFFic Rate dan Luas AREA

\begin{tabular}{|c|c|c|c|c|c|c|}
\hline \multicolumn{7}{|c|}{ Packet Delivery Ratio (\%) } \\
\hline $\begin{array}{l}\text { Luas } \\
\text { Area } \\
\left(\mathbf{m}^{2}\right)\end{array}$ & $\begin{array}{c}\text { Traffic } \\
\text { Rate }\end{array}$ & AOMDV & $\begin{array}{c}\text { AOMDV + } \\
\text { Wormhole } \\
\text { (WAOMDV) }\end{array}$ & $\begin{array}{c}\text { WAOMDV } \\
+ \\
\text { Delphi }\end{array}$ & $\begin{array}{c}\text { WAOMDV } \\
+ \\
\text { RTT-TC }\end{array}$ & $\begin{array}{c}\text { WAOMDV } \\
+ \\
\text { Gabungan } \\
\text { Metode }\end{array}$ \\
\hline \multirow{10}{*}{$\begin{array}{c}800 \mathrm{x} \\
800 \mathrm{~m}^{2}\end{array}$} & 0.1 & 71.836 & 30.928 & 48.800 & 61.975 & 67.701 \\
\hline & 0.2 & 47.199 & 19.965 & 29.884 & 42.879 & 43.561 \\
\hline & 0.3 & 45.520 & 15.280 & 28.174 & 39.377 & 42.402 \\
\hline & 0.4 & 45.021 & 13.533 & 26.544 & 40.149 & 41.903 \\
\hline & 0.5 & 45.455 & 13.876 & 27.325 & 39.530 & 41.987 \\
\hline & 0.6 & 44.801 & 14.271 & 26.895 & 39.390 & 41.085 \\
\hline & 0.7 & 44.056 & 15.370 & 27.163 & 37.670 & 40.518 \\
\hline & 0.8 & 45.119 & 14.768 & 27.726 & 37.862 & 40.300 \\
\hline & 0.9 & 44.473 & 14.914 & 27.418 & 36.513 & 39.669 \\
\hline & 1.0 & 43.569 & 14.580 & 27.207 & 37.406 & 39.264 \\
\hline $\begin{array}{c}\text { Luas } \\
\text { Area } \\
\left(\mathbf{m}^{2}\right)\end{array}$ & $\begin{array}{c}\text { Traffic } \\
\text { Rate }\end{array}$ & AOMDV & $\begin{array}{c}\text { AOMDV + } \\
\text { Wormhole } \\
\text { (WAOMDV) }\end{array}$ & $\begin{array}{c}\text { WAOMDV } \\
+ \\
\text { Delphi }\end{array}$ & $\begin{array}{c}\text { WAOMDV } \\
+ \\
\text { RTT-TC }\end{array}$ & $\begin{array}{c}\text { WAOMDV } \\
+ \\
\text { Gabungan } \\
\text { Metode }\end{array}$ \\
\hline \multirow{10}{*}{$\begin{array}{c}1000 \mathrm{x} \\
1000 \\
\mathrm{~m}^{2}\end{array}$} & 0.1 & 68.067 & 24.411 & 46.308 & 58.978 & 60.848 \\
\hline & 0.2 & 43.871 & 12.938 & 23.221 & 33.685 & 34.398 \\
\hline & 0.3 & 35.408 & 9.376 & 22.568 & 31.891 & 32.460 \\
\hline & 0.4 & 36.357 & 8.161 & 22.536 & 31.354 & 33.500 \\
\hline & 0.5 & 35.414 & 8.036 & 22.949 & 30.569 & 32.816 \\
\hline & 0.6 & 34.850 & 8.156 & 22.755 & 30.781 & 33.029 \\
\hline & 0.7 & 34.910 & 7.990 & 22.339 & 30.522 & 31.576 \\
\hline & 0.8 & 35.042 & 8.000 & 22.127 & 30.788 & 31.544 \\
\hline & 0.9 & 34.606 & 8.364 & 22.754 & 30.323 & 30.127 \\
\hline & 1.0 & 34.468 & 8.786 & 22.580 & 30.482 & 31.105 \\
\hline
\end{tabular}

\section{Perubahan Throughput Terhadap Traffic Rate dan} Luas Area

Berdasarkan Tabel IV, dapat diketahui bahwa nilai tertinggi throughput AOMDV pada saat kondisi normal adalah 3,01 Kbps, kemudian menurun menjadi 1,23 Kbps saat terdapat serangan wormhole. Nilai throughput kembali meningkat setelah diimplementasikan metode Delphi dan RTT-TC dan mencapai nilai tertinggi yakni $1,85 \mathrm{Kbps}$ pada saat menggunakan metode Delphi dan 2,57 Kbps pada saat menggunakan metode RTT-TC. Pada saat gabungan metode Delphi dan RTT-TC diimplementasikan, nilai throughput AOMDV menjadi lebih baik, yakni 2,65 Kbps. Sedangkan, nilai tertinggi throughput AOMDV pada saat kondisi normal adalah 2,37 Kbps kemudian menurun menjadi 0,77 Kbps saat terdapat serangan wormhole. Nilai throughput kembali meningkat setelah diimplementasikan metode Delphi dan RTT-TC dan mencapai nilai tertinggi, yakni $1,63 \mathrm{Kbps}$ pada saat menggunakan metode Delphi dan 2,06 Kbps pada saat menggunakan metode RTT-TC. Pada saat gabungan metode Delphi dan RTT-TC diimplementasikan, nilai throughput AOMDV menjadi lebih baik, yakni 2,09 Kbps.

TABEL IV. KuAlitas Throughput TerhadAP TRAFFic Rate DAN LUAS AREA

\begin{tabular}{|c|c|c|c|c|c|c|}
\hline \multicolumn{7}{|c|}{ Throughput (Kbps) } \\
\hline $\begin{array}{l}\text { Luas } \\
\text { Area } \\
(\mathrm{m} 2)\end{array}$ & $\begin{array}{c}\text { Traffic } \\
\text { Rate }\end{array}$ & AOMDV & $\begin{array}{c}\text { AOMDV + } \\
\text { Wormhole } \\
\text { (WAOMDV) }\end{array}$ & $\begin{array}{c}\text { WAOMDV } \\
+ \\
\text { Delphi }\end{array}$ & $\begin{array}{c}\text { WAOMDV } \\
+ \\
\text { RTT-TC }\end{array}$ & $\begin{array}{c}\text { WAOMDV } \\
+ \\
\text { Gabungan } \\
\text { Metode }\end{array}$ \\
\hline \multirow{10}{*}{$\begin{array}{c}800 \mathrm{x} \\
800 \\
\mathrm{~m}^{2}\end{array}$} & 0.1 & 0.55 & 0.26 & 0.37 & 0.45 & 0.48 \\
\hline & 0.2 & 0.67 & 0.33 & 0.43 & 0.61 & 0.61 \\
\hline & 0.3 & 0.99 & 0.39 & 0.59 & 0.84 & 0.92 \\
\hline & 0.4 & 1.23 & 0.49 & 0.72 & 1.13 & 1.15 \\
\hline & 0.5 & 1.58 & 0.62 & 0.95 & 1.39 & 1.46 \\
\hline & 0.6 & 1.86 & 0.69 & 1.10 & 1.66 & 1.67 \\
\hline & 0.7 & 2.15 & 0.84 & 1.28 & 1.84 & 1.92 \\
\hline & 0.8 & 2.41 & 0.97 & 1.54 & 2.09 & 2.21 \\
\hline & 0.9 & 2.73 & 1.11 & 1.69 & 2.29 & 2.44 \\
\hline & 1.0 & 3.01 & 1.23 & 1.85 & 2.57 & 2.65 \\
\hline $\begin{array}{l}\text { Luas } \\
\text { Area }\end{array}$ & $\begin{array}{c}\text { Traffic } \\
\text { Rate }\end{array}$ & AOMDV & $\begin{array}{c}\text { AOMDV + } \\
\text { Wormhole } \\
\text { (WAOMDV) }\end{array}$ & $\begin{array}{c}\text { WAOMDV } \\
+ \\
\text { Delphi }\end{array}$ & $\begin{array}{c}\text { WAOMDV } \\
+ \\
\text { RTT-TC }\end{array}$ & $\begin{array}{c}\text { WAOMDV } \\
+ \\
\text { Gabungan } \\
\text { Metode }\end{array}$ \\
\hline \multirow{10}{*}{$\begin{array}{c}1000 \mathrm{x} \\
1000 \\
\mathrm{~m}^{2}\end{array}$} & 0.1 & 0.52 & 0.20 & 0.32 & 0.44 & 0.45 \\
\hline & 0.2 & 0.54 & 0.23 & 0.35 & 0.49 & 0.50 \\
\hline & 0.3 & 0.76 & 0.26 & 0.49 & 0.65 & 0.67 \\
\hline & 0.4 & 1.01 & 0.31 & 0.67 & 0.87 & 0.93 \\
\hline & 0.5 & 1.21 & 0.38 & 0.83 & 1.05 & 1.13 \\
\hline & 0.6 & 1.44 & 0.47 & 0.98 & 1.26 & 1.36 \\
\hline & 0.7 & 1.70 & 0.50 & 1.13 & 1.47 & 1.52 \\
\hline & 0.8 & 1.91 & 0.59 & 1.28 & 1.72 & 1.73 \\
\hline & 0.9 & 2.12 & 0.68 & 1.47 & 1.89 & 1.87 \\
\hline & 1.0 & 2.37 & 0.77 & 1.63 & 2.06 & 2.09 \\
\hline
\end{tabular}

Pengimplementasian gabungan metode Delphi dan RTT-TC cukup efektif untuk meningkatkan kualitas throughput pada protokol routing AOMDV yang mengalami penurunan karena adanya serangan wormhole. Selain itu, nilai throughput pada area $800 \times 800 \mathrm{~m}^{2}$ juga lebih tinggi dibandingkan dengan area $1000 \mathrm{x} 1000 \mathrm{~m}^{2}$, karena pada luas area yang semakin bertambah menyebabkan jarak antara node yang satu dengan yang lainnya di suatu jaringan menjadi cukup jauh, sehingga menyebabkan semakin panjang rute yang akan dilewati untuk mencapai node tujuan.

Peningkatan traffic rate menyebabkan semakin cepat lalu lintas paket data. Hal ini juga menyebabkan semakin banyak paket data yang berhasil diterima oleh node tujuan serta waktu pengiriman paket data yang semakin cepat. 
Dengan adanya peningkatan traffic rate, kualitas delay semakin baik dan kualitas throughput semakin meningkat. Sedangkan, kualitas PDR semakin menurun seiring dengan peningkatan traffic rate. Hal ini disebabkan karena PDR tidak hanya dipengaruhi oleh jumlah paket data yang berhasil diterima saja, tetapi juga dipengaruhi oleh jumlah paket data yang dikirimkan. Semakin tinggi traffic rate, semakin banyak pula paket data yang dikirimkan dan berhasil diterima. Selisih antara paket yang dikirim dan diterima pun semakin meningkat. Kondisi inilah yang menyebabkan kualitas PDR semakin menurun seiring dengan peningkatan traffic rate.

\section{KESIMPULAN DAN SARAN}

\section{A. Kesimpulan}

Berdasarkan penelitian dan analisis yang telah dilakukan, maka diperoleh kesimpulan dan saran sebagai berikut.

1. Penerapan serangan wormhole menyebabkan peningkatan delay serta penurunan nilai PDR dan throughput pada protokol routing AOMDV.

2. Peningkatan traffic rate menyebabkan semakin cepat lalu lintas paket data. Hal ini menyebabkan semakin banyak paket data yang berhasil dikirimkan ke node tujuan serta waktu pengiriman paket data yang semakin cepat.

3. Perbedaan luas area dapat mempengaruhi perbedaan nilai average end-to-end delay, packet delivery ratio, dan throughput. Hal ini disebabkan karena semakin luas suatu area, maka pergerakan node semakin leluasa dan jarak antar node pada jaringan semakin jauh. Dari hasil simulasi yang diperoleh dapat diketahui bahwa, penambahan luas area menyebabkan average end-to-end delay semakin meningkat serta nilai PDR dan throughput semakin menurun seiring dengan adanya serangan wormhole.

4. Berdasarkan hasil pengujian, penerapan gabungan metode Delphi dan RTT-TC dapat mendeteksi dan mencegah serangan wormhole. Gabungan metode Delphi dan RTT-TC dapat menurunkan nilai delay serta meningkatkan nilai PDR dan throughput pada protokol routing AOMDV.

\section{B. Saran}

Pada penelitian yang akan datang diharapkan adanya simulasi dan pengujian pada berbagai macam protokol routing untuk mengetahui perbedaan kinerja di setiap protokol-protokol tersebut. Selain itu, diharapkan adanya variasi jumlah node penyerang serta pengujian kinerja menggunakan beberapa parameter uji lainnya untuk pengembangan penelitian yang lebih baik lagi.

\section{DAFTAR PUSTAKA}

[1] A. T. S. Putranto, Analisis Penggunaan Energy AODV dan DSDV pada Mobile Ad Hoc Network, Yogyakarta: Program Studi Teknik Informatika
Jurusan Teknik Informatika Fakultas Sains dan Teknologi Universitas Sanata Dharma, 2016.

[2] F. A. Jenefer and D. Vydeki, "Performance Analysis of Mobile Ad Hoc Network in the Presence of Wormhole Attack," International Journal of Advance Computer Engineering and Communication Technology, vol. 2, no. 1, pp. 22785140, February 2013.

[3] H. S. Chiu and K.-S. Lui, "DelPHI: Wormhole Detection Mechanism for Ad Hoc Wireless Networks," The 1st International Symposium on Wireless Pervasive Computing, February 2006.

[4] M. R. Alam, Detecting Wormhole and Byzantine Attacks in Mobile ad hoc Networks, Curtin University of Technology : School of Electrical and Computer Engineering, 2011.

[5] S. Kaushal and R. Aggarwal, "Avoidance of Wormhole Attack by Using Delphi Method," International Research Journal of Engineering and Technology, vol. 02, no. 07, October 2015.

[6] R. Kaur and A. Bansal, "Detection and Prevention of Wormhole Attack on AOMDV Routing Protocol using Hop-count and Communication Range in WSN," International Journal of Innovations \& Advancement in Computer Science, vol. 7, no. 4, April 2018.

[7] S. K. Arora and M. Ayushree, "Detection and Performance Analysis of Wormhole Attack in MANET Using DELPHI Technique," International Journal of Security and Its Applications, vol. 10, pp. 321-330, 2016.

[8] M. G. P. Sanaei, I. F. Isnin and M. Bakhtiari, "Performance Evaluation of Routing Protocol on AODV and DSR under Wormhole Attack," International Journal of Computer Networks and Communication Security, vol. 1, pp. 1-6, June 2013.

[9] B. B. Putra and R. Anggoro, "Studi Kinerja Multipath AODV dengan Menggunakan Network Simulator 2 (NS-2)," vol. 5, pp. A652-A656, 2016.

[10] F. A. Jenefer and D. Vydeki, "Performance Analysis of Mobile Ad Hoc Network in the Presence of Wormhole Attack," International Journal of Advance Computer Engineering and Communication Technology, vol. 2, no. 1, pp. 22785140, February 2013.

[11] H. S. Chiu and K.-S. Lui, "DelPHI: Wormhole Detection Mechanism for Ad Hoc Wireless Networks," February 2006.

[12] S. Shamaei and A. Movaghar, "A Two-Phase Wormhole Attack Detection Scheme in MANETs," The ISC int'l of Information Security, vol. 6, pp. 183191, July 2014. 